\title{
Effects of Educational and Cultural Facilities on Housing Prices in Seoul from an Accessibility Perspective
}

\author{
Minki Sung ${ }^{1}$ and Junghoon $\mathrm{Ki}^{2 *}$ \\ ${ }_{1}^{1}$ Postgraduate student, Department of Archaeology, Durham University, Durham DH1 3LE, United Kingdom \\ ${ }^{2}$ Professor, Department of Public Administration, School of Social Science, Myongji University, Seoul 03674, South Korea
}

\begin{abstract}
Background and objective: A great deal of previous research has highlighted the value of educational and cultural facilities embedded in housing prices, by taking a large spatial area as the focus, such as the city or district level. However, few studies have investigated the extent to which educational and cultural facilities influence the formation of housing prices from an accessibility perspective. This study aims to identify the value of educational and cultural facilities embedded in the housing prices in Seoul Metropolitan City with a focus on the concept of the residents' neighbourhood and accessibility. Methods: To this end, this research used a spatial regression model with educational and cultural facilities as the independent variables and housing prices as the dependent variable. The model assessed the accessibility of cultural and educational facilities by considering geographic effects.

Results: The findings are as follows. First, the spatial error model was found to be the best fit for multi-unit housing, while the spatial lag model was more appropriate for single-unit housing and apartments. Second, private educational facilities and art museums had positive effects on single- and multi-unit housing prices, while historical sites had a negative effect. Finally, private educational facilities positively influenced apartment prices, whereas public libraries and urban park areas had a negative effect.

Conclusion: These findings indicate that the accessibility of educational and cultural facilities reflects residents' preferences and needs, which will ultimately influence housing prices.
\end{abstract}

Keywords: neighbourhood; public facilities; residents' preference; spatial regression model

\section{Introduction}

How is housing appraised? Are the physical characteristics of housing the only indicators of its value? While these have been ongoing questions in housing research, many researchers have also discussed housing prices per se or in relation to locational characteristics (Dong et al., 2019; Li et al., 2019; Wittowsky et al., 2020). In reality, housing prices reflect not only the physical characteristics of a house itself but also the various elements of its location and surrounding environment (Adair et al., 2000; Dong et al., 2019; Lan et al., 2018; Li et al., 2019; Zahirovic-Herbert and Gibler, 2020).
In particular, the neighbourhood plays an important role (Bramley et al. 2008; Lan et al., 2018; Wittowsky et al., 2020), in that housing prices vary significantly among different submarkets segmented according to accessibility (Adair et al., 2000; Feng et al., 2020; Ki and Sung, 2020; Sung and Ki, 2021).

Previous Seoul-based case studies, which mainly focused on how urban public facilities affect housing prices over a large area, such as a residential district (Jin and Sohn, 2005; Kim, 2012; Kim and Lee 2007; Lee, 2010), have primarily addressed the extent to which access to educational facilities influences housing prices. Further, recent studies on cultural facilities and green spaces have explicitly demonstrated that

This work was supported by the National Research Foundation of Korea [grant number: NRF-2017R1D1A1B03032415]

Received: July 6, 2021, Revised: August 10, 2021, Accepted: September 13, 2021

First author: Minki Sung, mingi5678@nate.com, (10) https://orcid.org/0000-0001-6665-9383

*Corresponding author: Junghoon Ki, johnki70@gmail.com, (D) https://orcid.org/0000-0001-7554-9573 
residents appreciate residential areas with access to cultural facilities and green spaces, and that housing prices vary according to this accessibility (Kang, 2014; Park et al., 2017; Sung and Ki, 2021; Yim and Kim, 2020; Yuan et al., 2020).

But thus far, few studies have explored urban public facilities in terms of accessibility within the residents' immediate neighbourhoods; namely, the area covering a radius of approximately 700 meters from one's residence. In particular, cultural and educational facilities in close proximity (i.e., located at a psychologically comfortable walking distance from a resident's dwelling) have been rarely considered (Oh, 2014). Therefore, this study aims to analyse easily accessible educational and cultural facilities, following $\mathrm{Ki}$ and Sung (2020), to bridge the abovementioned research gap in housing studies. Specifically, it addresses the lack of studies on housing price formation by employing the concept of accessibility for residents, thereby contributing to housing policy.

The remainder of this paper is organized as follows. In the next section, we discuss the research methods and processes based on a review of the related literature to determine the theoretical background and analysis framework. In Section 3 , this study presents and interprets the research results, and Section 4 provides the conclusions and implications of the findings.

\section{Research Methods}

\section{Study framework}

Previously, the main location factors that have been identified as influencing housing prices included accessibility of the central business district (CBD), transportation costs, or the spatial pattern of amenities in a city. Specifically, the AlonsoMuth-Mills (AMM) urban economic model suggests a monocentric urban structure, in which housing prices close to the CBD are higher than their suburban counterparts due to the additional transportation costs for accessing the CBD (Kulish et al., 2012). However, this model does not work effectively in a polycentric spatial structure because it fails to consider certain complex behaviours (Wittowsky et al., 2020).

Brueckner et al. (1999) suggested that, unlike in the AMM model, the spatial pattern of amenities can determine the hous- ing prices in a city. In particular, wealthy people prefer central locations or urban centres, which provide better amenities over suburban areas, and this phenomenon increases housing prices in central locations (Cai et al., 2020). Similarly, Van Duijn and Rouwendal (2012) revealed that, within a local context, the majority rule and preferences of residents are likely to determine the level of public goods provided. This can thus influence the attractiveness of a neighbourhood, and in turn, housing prices (Dong et al., 2019).

As such, one of the most prominent factors in choosing a residence is the housing price, because it reflects residents' public facility preferences (Decoville and Klein, 2020; Lan et al., 2018; Li et al., 2019; Wittowsky et al., 2020). Many scholars have found that housing prices are influenced by public facilities, with their benefits being evaluated according to their accessibility (Lan et al., 2018). Therefore, the spatial distribution of public facilities determines their accessibility for residents, while the place of residence seems to affect public infrastructure services and satisfaction with service accessibility (Decoville and Klein, 2020). Consequently, location and accessibility have proven to be crucial factors in explaining residential housing prices (Yuan et al., 2020), because amenity services within walking distance of residential dwellings influence nearby housing prices (Wittowsky et al., 2020).

To consider the actual factors related to location and accessibility, the Korean Ministry of Land, Infrastructure, and Transport (MOLIT) suggested basic infrastructure and minimum standards for living (Government of the Republic of Korea, 2018a). Based on these criteria, Seoul Metropolitan City (2019) provided clear guidelines under the 2030 Community Plan regarding what types of public facilities should be provided within a 10-minute walking distance from a residential dwelling (Table 1).

Recently, the Korean government implemented the concept of residents' immediate neighbourhood in real-life settings under a three-year plan for providing community social overhead capital (SOC). According to the Office for Government Policy Coordination of South Korea (Government of the Republic of Korea, 2019), community SOC is designed to improve the lives of residents by providing public services in the areas of culture, sports, childcare, education, and welfare.

Recent studies have emphasized the roles of educational and cultural facilities, with a focus on resident accessibility within 
the SOC concept (Lan et al., 2018; Li et al., 2019; Sagger et al., 2021). Li et al. (2019) confirmed that public service amenities (educational facilities, urban parks, and hospitals) and their accessibility significantly shape the housing market, claiming that educational and cultural facilities (parks, educational facilities, and private service amenities such as museums) increase housing prices in inner-city areas (Li et al., 2019). Sagger et al. (2021) adopted hedonic pricing methods using housing prices to evaluate the benefits of cultural facilities (historic buildings, archaeological sites, art museums, museums, and libraries) to society, and revealed that access to cultural facilities has many benefits. For example, Arts Council England argued that people value a visit to a local gallery at an average over GBP 5 , while Historic England suggested that households value the historic character of their local street at approximately GBP 7.80 per year (Government of the United Kingdom, 2021). However, Lan et al. (2018) argued that the benefits of educational and cultural facilities on housing prices vary with locational characteristics.

A plethora of recent Seoul-based case studies have demonstrated that housing prices are associated with educational and cultural facilities, with a focus on accessibility (Cho et al., 2020; Ha and Lee, 2013; Kim et al., 2015; Kim and Kim, 2019). For the element of educational facilities, Ha and Lee (2013) revealed that housing prices are most significantly influenced by a house's proximity to a private educational facility. Similarly, Kim and Kim (2019) and Cho et al. (2020) suggested that the number of private educational facilities and their cluster areas have positive influences on apartment prices. In addition, the accessibility of public libraries is related to housing prices in Seoul, implying that public libraries can positively or negatively influence housing prices by their accessibility. Kim et al. (2015) claimed that the location of public libraries should be determined using the concept of psychologically comfortable walking distance from a resident's dwelling.

Regarding cultural facilities, Kang (2014) claimed that Seoul residents tend to live in the city to enjoy the benefits of urban public facilities, such as art museums and urban parks. Furthermore, he suggested that museums are essential urban public facilities for increasing people's satisfaction with their residences. In particular, urban museums and art galleries have demonstrated their social benefits as highquality public spaces within communities (Lord and Blankenberg, 2016; Weill, 2002), which could improve residents' environmental satisfaction, and consequently, increase the prices of neighbouring housing. Park et al. (2017) also found that housing prices in Seoul vary depending on urban park accessibility, emphasizing that access to an urban park on foot is essential to increasing the monetary value of houses. However, Sung and Ki (2021) revealed that urban parks could also negatively influence residents' environmental satisfaction, as noise arising from a nearby urban park may adversely affect housing prices.

Moreover, historical sites, as important urban public amenities, and the proximity to an historical building are associated with residents' quality of life and well-being, which consequently influence housing prices (Ahlfeldt et al., 2012; Maeer et al., 2016; Moro et al., 2013; Rudokas et al., 2019; Smith et al., 2017). For example, Maeer et al. (2016) suggested that visiting historical sites has a significant positive effect on life satisfaction. This was supported by Reilly et al. (2018), who claimed that visiting historic sites can be

Table 1. Combined results of the 2030 Community Plan for educational and cultural facilities

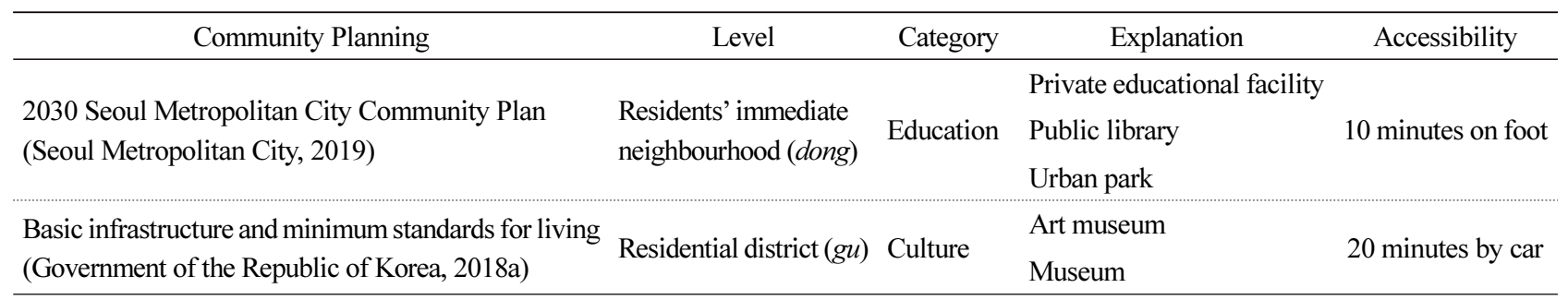

Note: Reconfigured based on basic infrastructure and minimum standards for living (Government of the Republic of Korea, 2018) and the 2030 Seoul Metropolitan City Community Plan (Seoul Metropolitan City, 2019). Urban parks include small parks, children's parks, and neighbourhood parks. 
beneficial to individual health and well-being, thereby affecting housing prices (Rudokas et al., 2019). Thus, accessibility to historical sites has numerous positive benefits, such as improving people's quality of life and well-being, which consequently influence housing prices (Rudokas et al., 2019; Sagger et al., 2021).

Thus, these previous studies have demonstrated that accessibility plays an important role in the influence of educational and cultural facilities on housing prices. Previous research has identified educational facilities as including both private educational facilities and public libraries, while local cultural facilities include art museums, museums, historical sites, and urban parks (Ha and Lee, 2013; Kang, 2014; Kim and Kim, 2019; Park et al., 2017; Sung and Ki, 2021). Museums and art museums are regarded as different facilities according to the 'Museum and Art Gallery Support Act of South Korea' (Government of the Republic of Korea, 2018b). However, these studies did not consider the concept of residents' immediate neighbourhood, which is neither quantifiable nor embodied. Thus, this study aims to investigate the effects of educational and cultural facilities on housing prices using the concept of residents' immediate neighbourhood (radius of $700 \mathrm{~m}$ from their residence; Table 2).

This study employed a community index based on a 10minute walking distance as residents' neighbourhood concept (Table 2) to determine the value of educational (private educational facilities and public libraries) and cultural (art museums, museums, historical sites, and urban parks) facilities embedded in housing prices in Seoul, with a focus on the concept of accessibility. Among the cultural facilities, urban parks represent a health-related factor in the broad context of culture.

Proximity to residents' immediate neighbourhood (radius of $700 \mathrm{~m}$ from residence) is closely associated with easy access to educational and cultural facilities. The residential sub-districts (dong) analysed in this study are generally similar (Table 2 ), while the residential district ( $g u$ ) encompasses a relatively wider area, to which the concept of residents' immediate neighbourhood is difficult to apply (Table 2). Adair et al. (2000) suggested that accessibility does not elucidate variations in housing prices at the district level but has a discernible submarket-level effect. Furthermore, the structure of local housing markets indicates that physical housing type is the best criterion for defining submarkets (Adair and McGreal, 1994).

\section{Research area}

This study designates the unit of analysis as residents' immediate neighbourhood, which is similar in area to a dong - a Korean administrative unit (see Fig. 1 and Table 2). An accurate analysis is impossible without space considerations. Therefore, we use Geoda 1.14 software to take advantage of spatial regression models. The spatial data we analysed were sourced from the Census of Statistics at the Korean Geographic Statistical Information Service (http://kosis.kr/eng/).

This study aims to determine the effects of facility location on the education and cultural aspects of 424 dongs in Seoul. Public libraries and private educational facilities represented the educational factor, while for the cultural aspect, we examined the influence of art museums, museums, and historical sites, which have scarcely been covered in previous studies (Sagger et al., 2021). Moreover, we explored whether the accessibility of urban parks affects housing prices.

As previously mentioned, the spatial unit of analysis is the dong, and we examined housing prices in each of the 424 dongs in Seoul. Single-unit housing, multi-unit housing, and apartment prices were used as dependent variables to

Table 2. Comparison between residents' immediate neighbourhood and the corresponding administrative units

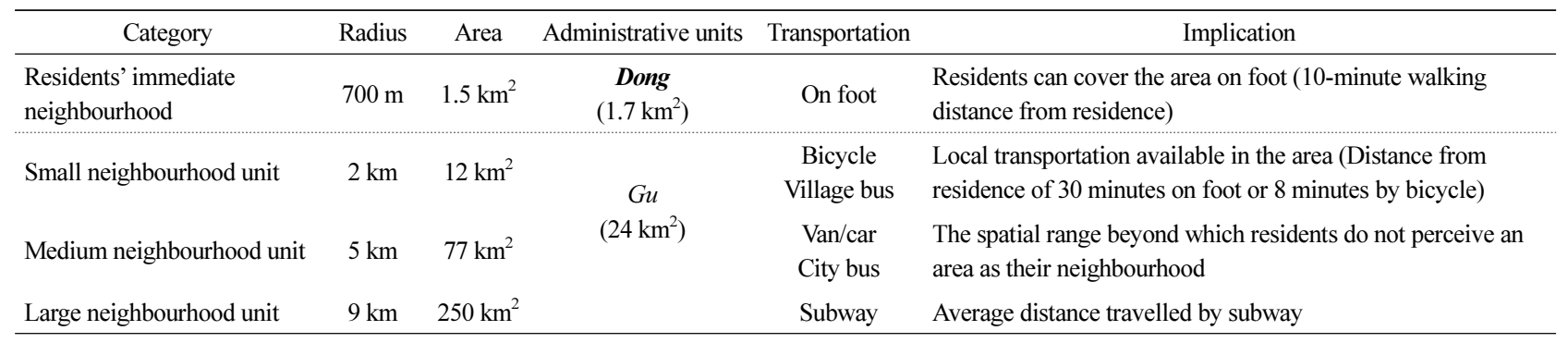

Note: Reconfiguration based on the content of Table 7 in Oh (2014) and actual map measurement results. 

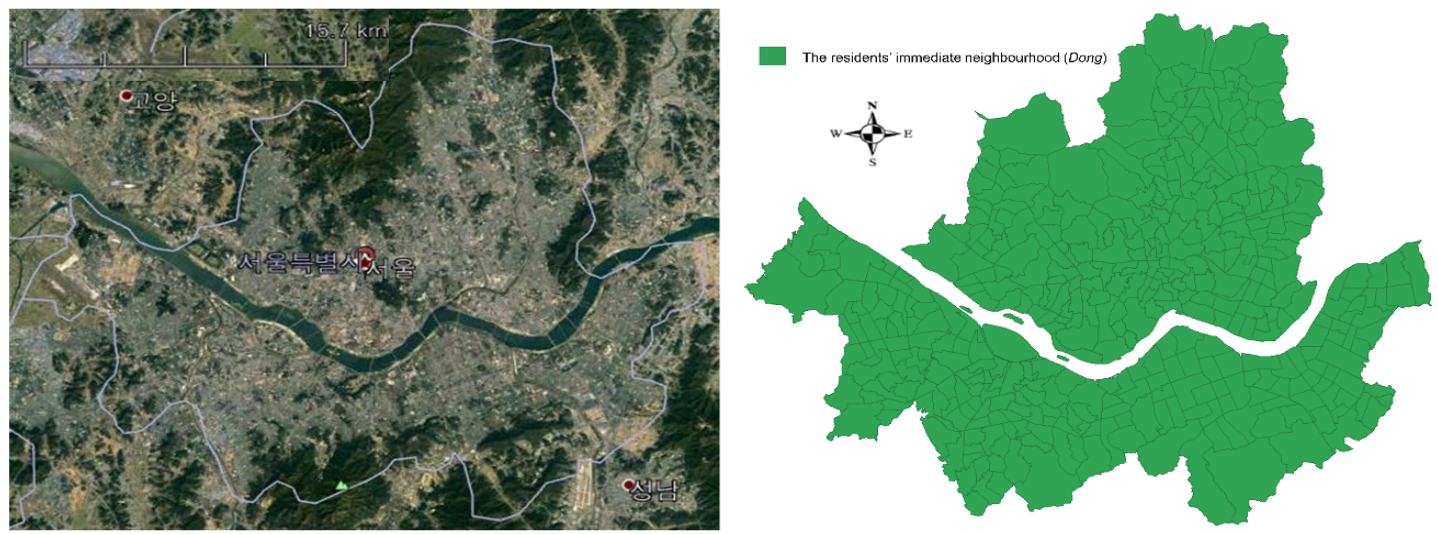

Fig. 1. Geological map of Seoul in relation to the concept of the resident immediate neighbourhood.

identify housing price determinants. Housing prices were calculated by dividing the total housing sale price by the total number of houses sold in 2016. Housing price data were sourced from an open system of the Land and Transport Department (https://rt.molit.go.kr/pre.html), while the corre sponding independent variable data were obtained from Seoul Open Data Plaza (https://data.seoul.go.kr/). The analysis period ends in 2016 for both datasets.

\section{Rationales used in choosing spatial regression model}

There are several methodological approaches to evaluating housing prices worldwide. Among them, the hedonic price model is a popular tool that has been adopted by many researchers. With three homogeneity assumptions for housing products - freedom to enter and exit the housing market, perfect information of housing products, and housing market equilibrium - the model has been widely used to analyse housing prices (Abidoye and Chan, 2017; Chin and Chau, 2003), and has been adopted for property price appraisals in different real estate markets worldwide. Its major advantage is the simplicity of comparing the value of real estate with property price, while its weakness is related to the difficulty of building experimental and control groups and the lack of consideration for the spatial effect of neighbouring areas.

Housing is a type of real estate with a geographical location, and is also considered a commodity with multidimensional socioeconomic, environmental, and physical characteristics (Chun, 2016). Housing has various interactions with the built environment, such as educational and cultural facilities, parks, or green spaces. Chun (2016) found a spatial correlation owing to the interaction between housing prices and adjacent housing prices. Kim and Chung (2010) also anticipated a high spatial autocorrelation in apartment prices, because most apartments collectively manage and use residential facilities within unit dwellings.

Therefore, this study utilized a spatial regression analysis to determine which educational and cultural factors affect housing prices. For this purpose, we adopted a spatial lag model (SLM) and a spatial error model (SEM) instead of an ordinary least squares (OLS) linear regression model.

We used spatial data on educational and cultural facilities' tangible assets and geographical locations. Therefore, a locationbased analysis was adopted to avoid a lack of consideration for spatial dependence and heterogeneity, as in the OLS method (Rey et al., 2016; Wittowsky et al., 2020). The assumption of independence between the observation and error values of the dependent variables in the OLS method can be inaccurate when spatial autocorrelation occurs from spatial dependence. Fig. 2 presents the results of an analysis of the global and local Moran's I, which suggest that every dependent variable in this study has spatial autocorrelation. Therefore, we analysed the data using spatial regression models to control for the spatial dependence.

Spatial regression analysis was employed to consider the spatial dependence of the geographical data. The spatial regression model is expressed as follows:

$$
\mathrm{Y}=\beta 0+\beta \mathbf{x}+\rho \mathrm{wy}+\varepsilon,
$$




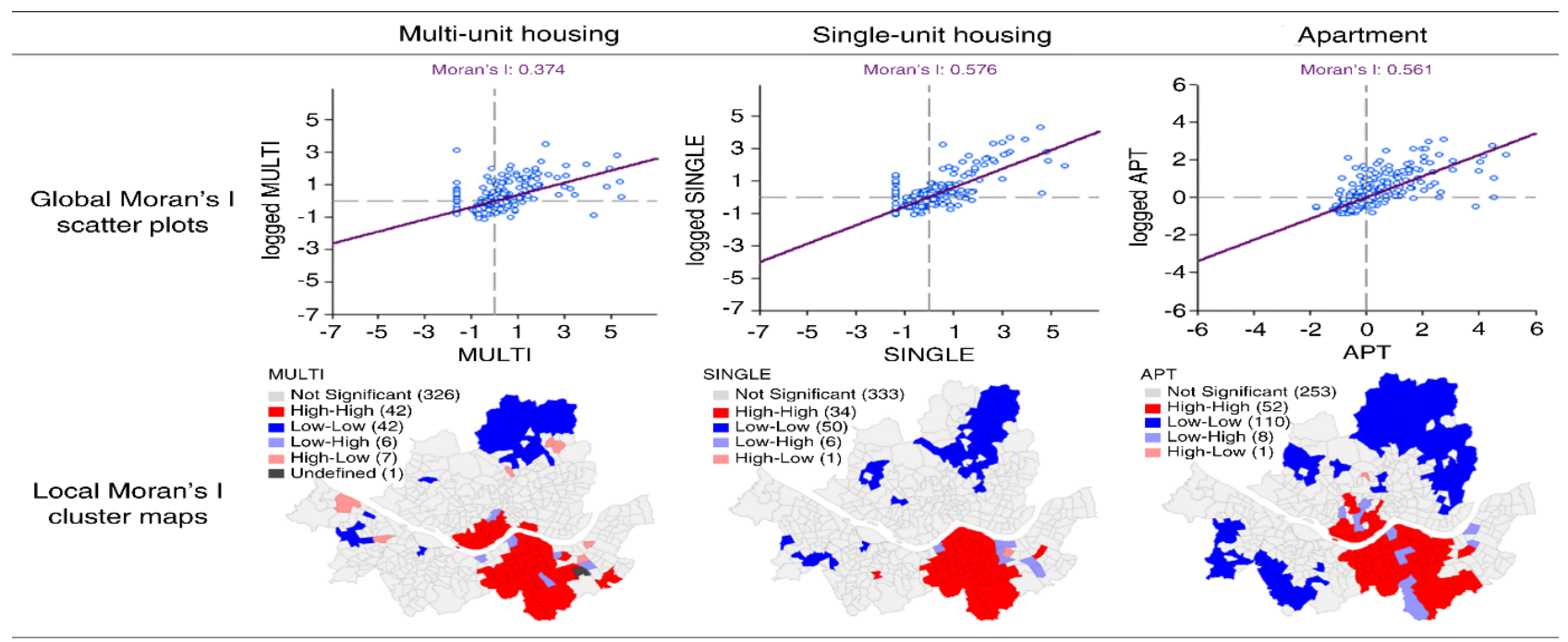

Fig. 2. Global and local Moran's I analysis results; MULTI: multi-unit housing, SINGLE: single-unit housing, APT: apartment.

where $\mathrm{Y}$ denotes the housing price, $\mathrm{x}$ is a matrix of observations on the explanatory variables, and $\rho$ wy is the spatial lag (or error) variable. $\rho$ assesses the degree of spatial correlation and $\mathrm{w}$ is the spatial weights matrix. The value of $\rho$ ranges between -1 and 1 , with $\rho=0$ signifying no spatial correlation. Under a positive $\rho$, housing prices are expected to be higher if spatially adjacent housing prices are higher, while $\varepsilon$ is a vector of the independent and equivalently distributed error terms (Ward and Gleditsch, 2008).

Spatial regression models include SLM and SEM, which use spatial regression dependencies and spatial regression errors, respectively. We determined which model was more suitable by comparing them with the results of the OLS model. The OLS model was tested for suitability under the assumptions of normality, equal variability, and spatial independence of errors (Park and Ham, 2018). Similarly, the spatial dependencies of dependent variables and regression model error terms were examined using the Lagrange multiplier (LM) lag and error. If the LM lag and error are meaningful at the 5\% significance level, the null hypothesis of the spatial independence of dependent variables and error terms is rejected. If only one of either the LM lag or error is statistically significant, selecting a more adequate model should be considered. If both values are significant, the robust LM lag and robust LM error statistics test functions are used for reselection, as a last resort (Park and Ham 2018). Park and Ham (2018) relied on the log-likelihood, Akaike information criterion (AIC), and Schwarz criterion (SC) results to determine the suitability of spatial regression models. Compared to the results of the OLS model, the model with a higher log-likelihood and lower AIC and SC was considered appropriate.

To determine the effects of educational and cultural factors, we used the number of public libraries and private educational facilities as a proxy for the educational factor (independent variable). Regarding the cultural factor, art museums, museums, historical sites, and urban parks are used as independent variables. Table 3 and Table 4 present detailed statistical information for the independent and dependent variables.

\section{Results and Discussion}

As shown in Fig. 3, we illustrated housing prices and their independent variables using ArcGIS 10.8. On average, the number of private educational facilities was large (31.65) and showed a high standard deviation (17.74) compared to other facilities. Fig. 3 also shows that private educational facilities tend to be clustered in the south-eastern part of Seoul, where housing prices are generally higher regardless of the housing type. However, public libraries had a relatively low standard deviation (1.26), implying that a similar number of public libraries are distributed across districts, as can also be seen in Fig. 3 .

As for cultural facilities, art museums, museums, and 
Table 3. Definitions of independent and dependent variables

\begin{tabular}{|c|c|c|c|c|}
\hline \multicolumn{3}{|c|}{ Variables } & \multicolumn{2}{|r|}{ Definition } \\
\hline \multirow{3}{*}{$\begin{array}{l}\text { Dependent } \\
\text { variable }\end{array}$} & \multirow{3}{*}{$\begin{array}{c}\text { Price by } \\
\text { housing type }\end{array}$} & Multi-unit housing & \multirow{3}{*}{$\begin{array}{l}\text { Real estate transaction } \\
\text { price }\end{array}$} & \multirow{3}{*}{$\begin{array}{l}\text { Housing types are classified as follows: single-unit } \\
\text { housing, multi-unit housing, or apartment. Single- and } \\
\text { multi-unit housing tends to be occupied by less affluent } \\
\text { families, whereas relatively affluent families reside in } \\
\text { apartments (Kang et al., 2019). More than half of the } \\
\text { population ( } 50.7 \% \text { ) in Seoul resides in apartments (Kang } \\
\text { et al., 2019). Furthermore, Jeon (2015) suggested that } \\
\text { most residents in Korea prefer apartments because an } \\
\text { apartment complex that has access to educational and } \\
\text { cultural facilities is more attractive than single- or } \\
\text { multi-unit dwellings when raising children. }\end{array}$} \\
\hline & & Single-unit housing & & \\
\hline & & Apartment & & \\
\hline \multirow{7}{*}{$\begin{array}{l}\text { Independent } \\
\text { variables }\end{array}$} & \multirow[t]{2}{*}{$\begin{array}{l}\text { Educational } \\
\text { factors }\end{array}$} & Public library & $\begin{array}{l}\text { Number of public libraries } \\
\text { in Seoul }\end{array}$ & $\begin{array}{l}\text { Public library means a library established and operated by } \\
\text { local government for information, reading activities, and } \\
\text { cultural activities by the public. The libraries we } \\
\text { employed as an independent variable are local public } \\
\text { libraries, not university or special libraries, specially built } \\
\text { for residents. }\end{array}$ \\
\hline & & Private educational facility & $\begin{array}{l}\text { Number of registered } \\
\text { private academies and } \\
\text { study centres in Seoul }\end{array}$ & $\begin{array}{l}\text { Private educational facilities in this study are categorized } \\
\text { into two types: those with curricula that facilitate entrance } \\
\text { into prestigious universities and those providing lifelong } \\
\text { or vocational education. }\end{array}$ \\
\hline & \multirow{5}{*}{ Cultural factors } & Art museum & $\begin{array}{l}\text { Number of art museums in } \\
\text { Seoul }\end{array}$ & \multirow{2}{*}{$\begin{array}{l}\text { The reason for distinguishing museums from art museums } \\
\text { is that the Museum and Art Gallery Support Act of South } \\
\text { Korea (Government of the Republic of Korea, 2018b) } \\
\text { considers them to be different. }\end{array}$} \\
\hline & & Museum & $\begin{array}{l}\text { Number of museums in } \\
\text { Seoul }\end{array}$ & \\
\hline & & Historical site & $\begin{array}{l}\text { Number of historical sites } \\
\text { in Seoul }\end{array}$ & $\begin{array}{l}\text { In this study, historical sites cover every historical } \\
\text { property registered by central and local governments. In } \\
\text { South Korea, historical sites can be categorized into three } \\
\text { types: nationally assigned cultural properties, city } \\
\text { assigned properties, and nationally registered properties. }\end{array}$ \\
\hline & & Number of urban parks & $\begin{array}{l}\text { Number of urban parks in } \\
\text { Seoul }\end{array}$ & \multirow{2}{*}{$\begin{array}{l}\text { The park concept we employed in this study includes } \\
\text { parks established and managed within the urban residents' } \\
\text { immediate neighbourhood structure; it includes } \\
\text { small-sized, children's, and neighbourhood parks. }\end{array}$} \\
\hline & & Urban park area & Urban park areas in Seoul & \\
\hline
\end{tabular}

Table 4. Descriptive statistics of independent and dependent variables

\begin{tabular}{|c|c|c|c|c|c|c|}
\hline \multirow{2}{*}{\multicolumn{3}{|c|}{ Variable }} & \multicolumn{4}{|c|}{ Dong (sub-district) } \\
\hline & & & Average & Standard deviation & Max & Min \\
\hline \multirow{3}{*}{$\begin{array}{l}\text { Dependent } \\
\text { variable }\end{array}$} & \multirow{3}{*}{ Price by housing type } & Multi-unit housing & 249688516.3 & 155834809.2 & 1100000000 & 104363359.5 \\
\hline & & Single-unit housing & 831456068.7 & 617399014.6 & 4288716364 & 190000000 \\
\hline & & Apartment & 517997051 & 290439973.6 & 1956893793 & 183663265.3 \\
\hline \multirow{7}{*}{$\begin{array}{l}\text { Independent } \\
\text { variables }\end{array}$} & \multirow[b]{2}{*}{ Educational factor } & Public library & 1.43 & 1.26 & 20 & 0 \\
\hline & & $\begin{array}{l}\text { Private educational } \\
\text { facility }\end{array}$ & 31.65 & 17.74 & 195 & 0 \\
\hline & \multirow{5}{*}{ Cultural factor } & Art museum & 0.11 & 0.57 & 7 & 0 \\
\hline & & Museum & 0.26 & 1.14 & 11 & 0 \\
\hline & & Historical site & 0.35 & 3.16 & 49 & 0 \\
\hline & & Number of urban parks & 6.05 & 2.53 & 27 & 0 \\
\hline & & Urban park area & $0.06 \mathrm{~km}^{2}(4 \%)$ & 0.97 & $14.55 \mathrm{~km}^{2}(80 \%)$ & $0.00003 \mathrm{~km}^{2}(0.01 \%)$ \\
\hline
\end{tabular}

Note: All independent variables are expressed per 10,000 population. Urban park areas are expressed as a proportion of the total sub-district (dong) area. The unit of housing price is Korean won. 
historical sites are primarily clustered in the centre of Seoul (Fig. 3), because the centre of Seoul has a number of nationallyrecognised historical sites, such as Gyeongbokgung, Deoksugung, and Changgyeonggung, where relevant museums and art museums tend to be clustered together. Additionally, except for the centre of Seoul, relatively more museums and art museum are located in the south-eastern part of Seoul than in other areas, thus showing a similar spatial pattern to private educational facilities.

We confirmed the robustness and reliability of the models using a collinearity test to identify the correlation between the independent variables. The test revealed a variance inflation factor below 10 for each independent variable (Table 5), meaning the independent variables were not correlated.

We adopted an exploratory data analysis approach to select the most suitable spatial regression model for this study. To this end, we examined the appropriateness of each model using the Jarque-Bera, Breusch-Pagan, Koenker-Bassett, and White test statistics. Subsequently, the optimal model was determined using the conformity index among the OLS model, SLM, and SEM.

Table 5. Collinearity test results for the independent variables

\begin{tabular}{ccc}
\hline Independent variable & Tolerance & Variance inflation factor \\
\hline Public library & 0.697 & 1.435 \\
Private educational facility & 0.981 & 1.019 \\
Art museum & 0.491 & 2.037 \\
Museum & 0.657 & 1.521 \\
Historical site & 0.561 & 1.782 \\
Number of urban parks & 0.652 & 1.534 \\
Urban park area & 0.810 & 1.234 \\
\hline
\end{tabular}

Model selection and suitability depended on the values of $R^{2}$, log-likelihood, AIC, and SC. The most reliable model was determined using increasing values of $R^{2}$ and log-likelihood and the decreasing values of AIC and SC (Lee and Noh 2013). When these values pointed to different conclusions, the final model was identified by examining the LM (Seo et al., 2016). Further, if the final model provided a statistically significant result for rho (SLM) or lambda (SEM), this was used to explain the spatial spillover effect (Seo, 2014).

Table 6 displays the analysis results of the OLS model, SLM, and SEM using multi-unit housing prices as the dependent variable. First, we examined the results of the OLS model using the Jarque-Bera, Breusch-Pagan, and White test statistics. The Jarque-Bera test statistic is $1733.0079(p<.05)$, which signifies an abnormality in the spatial autocorrelation test of error terms. Furthermore, the Breusch-Pagan (19.1758, $p<.05)$ and White $(60.6184, p<.05)$ test statistics indicate heteroscedasticity in the error term. Therefore, this test points to spatial regression models instead of the OLS model.

By examining the results of the spatial regression model analysis, we selected the more suitable model between the SLM and SEM. The $R^{2}$ value $(0.085678)$ of the SEM is more robust and higher than that of the SLM. The log-likelihood value of the SEM $(-8,560.70)$ is higher and their AIC and SC are lower than those of the SLM. Consequently, we considered the SEM more suitable and found that private educational facilities and art museums positively influence the prices of multi-unit housing, whereas historical sites have a negative effect.

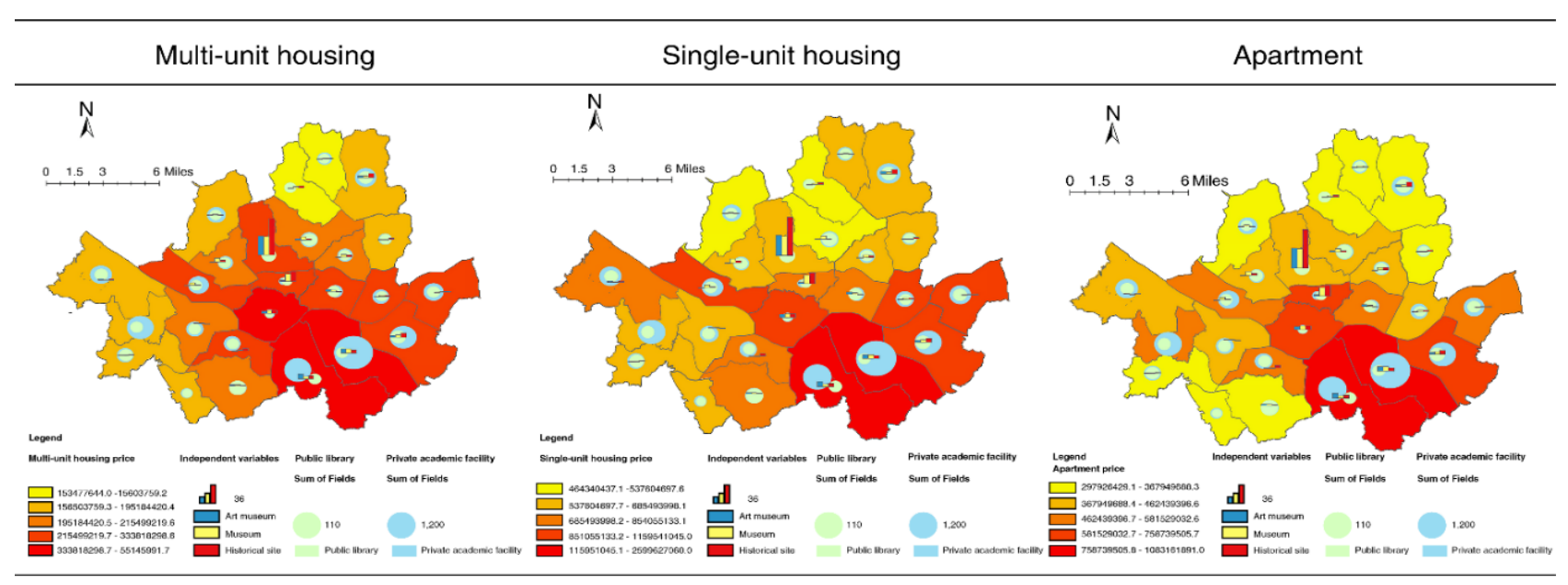

Fig. 3. Spatial distribution of housing prices and the corresponding independent variables for Seoul. 
Table 6. Analysis of multi-unit housing

\begin{tabular}{|c|c|c|c|c|}
\hline Dependent vari & multi-unit housing) & OLS & SLM & SEM \\
\hline \multicolumn{2}{|c|}{ Constant } & $2.53016 \mathrm{e}+008^{* * *}$ & $2.30529 \mathrm{e}+008^{* * *}$ & $2.52693 \mathrm{e}+008^{* * *}$ \\
\hline \multirow{2}{*}{ Educational factor } & Public library & $-1.14233 \mathrm{e}+007$ & $-1.18353 e+007$ & $-1.21706 e+007$ \\
\hline & Private educational facility & $548281^{* *}$ & $546127^{* *}$ & $544701^{* *}$ \\
\hline \multirow{5}{*}{ Cultural factor } & Art museum & $8.81226 \mathrm{e}+007^{* * *}$ & $8.72462 \mathrm{e}+007^{* * *}$ & $8.69073 \mathrm{e}+007^{* * *}$ \\
\hline & Museum & $4.83881 \mathrm{e}+006$ & $6.14577 \mathrm{e}+006$ & $6.9372 \mathrm{e}+006$ \\
\hline & Historical site & $-1.37727 \mathrm{e}+007^{* * *}$ & $-1.39005 \mathrm{e}+007^{* * *}$ & $-1.39798 \mathrm{e}+007^{* * *}$ \\
\hline & Number of urban parks & $-1.28692 \mathrm{e}+006$ & $-1.21817 \mathrm{e}+006$ & $-1.16495 e+006$ \\
\hline & Urban park area & -0.996065 & -0.957873 & -0.914984 \\
\hline \multicolumn{2}{|c|}{ Rho } & & 0.0890597 & \\
\hline \multicolumn{2}{|c|}{ Lambda } & & & 0.092414 \\
\hline \multicolumn{2}{|c|}{$R^{2}$} & 0.081162 & 0.085508 & 0.085678 \\
\hline \multicolumn{2}{|c|}{ Adj. $R^{2}$} & 0.065664 & & \\
\hline \multicolumn{2}{|c|}{ Log-likelihood } & -8561.41 & -8560.71 & -8560.70 \\
\hline \multicolumn{2}{|c|}{ Akaike information criterion } & 17138.8 & 17139.4 & 17137.4 \\
\hline \multicolumn{2}{|c|}{ Schwarz criterion } & 17171.2 & 17175.9 & 17169.8 \\
\hline \multicolumn{2}{|c|}{ Koenker-Bassett } & 3.5660 & & \\
\hline \multicolumn{2}{|c|}{ Breusch-Pagan } & $19.1758^{* *}$ & 18.8382 & 18.8002 \\
\hline \multicolumn{2}{|c|}{ White test } & $60.6184^{* *}$ & & \\
\hline \multicolumn{2}{|c|}{ Moran's I } & 1.3146 & & \\
\hline \multicolumn{2}{|c|}{ Lagrange multiplier (lag) } & 1.4785 & & \\
\hline \multicolumn{2}{|c|}{ Robust LM (lag) } & 0.0085 & & \\
\hline \multicolumn{2}{|c|}{ Lagrange multiplier (error) } & 1.4964 & & \\
\hline \multicolumn{2}{|c|}{ Robust LM (error) } & 0.0265 & & \\
\hline \multicolumn{2}{|c|}{ Likelihood ratio test } & & 0.23762 & 1.4261 \\
\hline
\end{tabular}

Note: ${ }^{*} p<.05,{ }^{* *} p<.01,{ }^{* * *} p<.001$. OLS: ordinary least squares; SLM: spatial lag model; SEM: spatial error model; LM: Lagrange multiplier.

Table 7 presents the analysis results of the OLS model, SLM, and SEM using single-unit housing price as the dependent variable. The Jarque-Bera test statistic of 1286.0811 $(p<.05)$ signifies an abnormality in the spatial autocorrelation test of error terms. Therefore, this test leads to spatial regression models instead of the OLS model. Using the results of the spatial regression model analysis, we selected the more suitable model between SLM and SEM. The $R^{2}$ value (0.303476) of the SLM is higher than that of the SEM, and is also more robust. Additionally, the log-likelihood value of the SLM $(-9,084.95)$ is higher and their AIC and SC are lower than those of the SEM. Furthermore, the likelihood ratio test of the SLM generates statistically significant results, indicating it is more suitable than the SEM.

For this reason, the SLM was considered the most suitable model based on the analysis results. The SLM results reveal that educational (private educational facilities) and cultural (art museums) factors exert positive influences on singleunit housing prices. However, historical sites adversely affect single-unit housing prices.

Table 8 shows the analysis results of the OLS model, SLM, and SEM using apartment price as the dependent variable. The Jarque-Bera test statistic of 1,008.7673 $(p<.05)$ signifies an abnormality in the spatial autocorrelation test of the error term. Moreover, the Breusch-Pagan test statistic (26.1987, $p<.05)$ indicates heteroscedasticity in the error term. Therefore, spatial regression models are preferrable to the OLS model.

The spatial regression model analysis allowed the most suitable model between the SLM and SEM to be selected. The $\mathrm{R}^{2}$ value $(0.171330)$ of the SLM was more robust and higher than that of the SEM. Moreover, the log-likelihood value of the SLM $(-8,803.23)$ was higher and the SC lower 
than that of the SEM. For this reason, the SLM was regarded to be the most suitable based on the analysis results. The results reveal that the educational factor exerted both positive (private educational facilities) and negative (public libraries) influences on apartment prices. This finding is important, because while public libraries were statistically significant in the spatial regression model, they were insignificant in the OLS one. This indicates that spatial regression analysis considers spatial effects and must be applied to measure the spillover effects of sites with a specific space.

Table 7. Analysis of single-unit housing

\begin{tabular}{|c|c|c|c|c|}
\hline \multicolumn{2}{|c|}{ Dependent variable (single-unit housing) } & OLS & SLM & SEM \\
\hline \multicolumn{2}{|c|}{ Constant } & $6.52325 \mathrm{e}+008^{* * *}$ & $5.36521 \mathrm{e}+008^{* * *}$ & $6.5393 \mathrm{e}+008$ \\
\hline \multirow{2}{*}{ Educational factors } & Public library & $-2.79845 e+007$ & $-2.76873 e+007$ & $-2.86462 \mathrm{e}+007$ \\
\hline & Private educational facility & $2.79395 \mathrm{e}+008^{* * *}$ & $7.4858 \mathrm{e}+006^{* * *}$ & $7.5038 \mathrm{e}+006^{* * *}$ \\
\hline \multirow{5}{*}{ Cultural factors } & Art museum & $258232550.280^{* * *}$ & $2.68802 \mathrm{e}+008^{* * *}$ & $2.68357 \mathrm{e}+008^{* * *}$ \\
\hline & Museum & $6.32358 \mathrm{e}+007$ & $6.68108 \mathrm{e}+007$ & $6.65248 \mathrm{e}+007$ \\
\hline & Historical site & $-3.71002 \mathrm{e}+007^{* * *}$ & $-3.78481 \mathrm{e}+007^{* *}$ & $-3.84802 \mathrm{e}+007^{* *}$ \\
\hline & Number of urban parks & $-6.80577 \mathrm{e}+006$ & $-6.92999 e+006$ & $-6.8878 \mathrm{e}+006$ \\
\hline & Urban park area & -6.46759 & -5.90286 & -5.8235 \\
\hline \multicolumn{2}{|c|}{ Rho } & & 0.0890597 & \\
\hline \multicolumn{2}{|c|}{ Lambda } & & & 0.10986 \\
\hline \multicolumn{2}{|c|}{$R^{2}$} & 0.293818 & 0.303476 & 0.298736 \\
\hline \multicolumn{2}{|c|}{ Adj. $R^{2}$} & 0.281906 & & \\
\hline \multicolumn{2}{|c|}{ Log-likelihood } & -9087.08 & -9084.95 & -9086.07 \\
\hline \multicolumn{2}{|c|}{ Akaike information criterion } & 18190.2 & 18187.9 & 18188.1 \\
\hline \multicolumn{2}{|c|}{ Schwarz criterion } & 18222.5 & 18224.3 & 18220.5 \\
\hline \multicolumn{2}{|c|}{ Koenker-Bassett } & 2.5375 & & \\
\hline \multicolumn{2}{|c|}{ Breusch-Pagan } & 12.4651 & 11.8637 & 2.0222 \\
\hline \multicolumn{2}{|c|}{ White test } & 41.6741 & & \\
\hline \multicolumn{2}{|c|}{ Moran's I } & 1.5495 & & \\
\hline \multicolumn{2}{|c|}{ Lagrange multiplier (lag) } & $4.6786^{*}$ & & \\
\hline \multicolumn{2}{|c|}{ Robust LM (lag) } & $3.9209^{*}$ & & \\
\hline \multicolumn{2}{|c|}{ Lagrange multiplier (error) } & 2.1215 & & \\
\hline \multicolumn{2}{|c|}{ Robust LM (error) } & 1.3638 & & \\
\hline \multicolumn{2}{|c|}{ Likelihood ratio test } & & $4.2727^{*}$ & 2.0222 \\
\hline
\end{tabular}

Note: ${ }^{*} p<.05,{ }^{* *} p<.01,{ }^{* * *} p<.001$. OLS: ordinary least squares; SLM: spatial lag model; SEM: spatial error model; LM: Lagrange multiplier.

Table 8. Analysis of apartments

\begin{tabular}{ccccc}
\hline \multicolumn{2}{c}{ Dependent variable (apartment) } & OLS & SLM & SEM \\
\hline \multicolumn{2}{c}{ Constant } & $4.76082 \mathrm{e}+008^{* * *}$ & $4.84887 \mathrm{e}+008^{* * *}$ & $4.76125 \mathrm{e}+008^{* * *}$ \\
\multirow{2}{*}{ Educational factors } & Public library & $-2.39781 \mathrm{e}+007$ & $-2.39659 \mathrm{e}+007^{*}$ & $-2.39323 \mathrm{e}+007^{*}$ \\
& Private educational facility & $2.5649 \mathrm{e}+006^{* * *}$ & $2.56447 \mathrm{e}+006^{* * *}$ & $2.5631 \mathrm{e}+006^{* * *}$ \\
& Art museum & $4.78958 \mathrm{e}+007$ & $4.83697 \mathrm{e}+007$ & $4.81688 \mathrm{e}+007$ \\
\multirow{3}{*}{ Cultural factors } & Museum & $3.89872 \mathrm{e}+007$ & $3.87268 \mathrm{e}+007$ & $3.88224 \mathrm{e}+007$ \\
& Historical site & $-5.82057 \mathrm{e}+006$ & $-5.82256 \mathrm{e}+006$ & $-5.81122 \mathrm{e}+006$ \\
& Number of urban parks & -678318 & -668196 & -678375 \\
& Urban park area & $-6.0852^{* *}$ & $-6.10283^{* *}$ & $-6.09184^{* *}$
\end{tabular}


Table 8. Continued

\begin{tabular}{|c|c|c|c|}
\hline Dependent variable (apartment) & OLS & SLM & SEM \\
\hline Rho & & -0.0169392 & \\
\hline Lambda & & & -0.006901 \\
\hline$R^{2}$ & 0.171184 & 0.171330 & 0.171206 \\
\hline Adj. $R^{2}$ & 0.157204 & & \\
\hline Log-likelihood & -8803.26 & -8803.23 & -8803.253223 \\
\hline Akaike information criterion & 17622.5 & 17624.5 & 17622.5 \\
\hline Schwarz criterion & 17654.9 & 17660.9 & 17654.9 \\
\hline Koenker-Bassett & 6.2613 & & \\
\hline Breusch-Pagan & $26.1987^{* * *}$ & $26.0083^{* * *}$ & $26.1088^{* * *}$ \\
\hline White test & 36.1292 & & \\
\hline Moran's I & -0.0090 & & \\
\hline Lagrange multiplier (lag) & 0.0560 & & \\
\hline Robust LM (lag) & 0.2264 & & \\
\hline Lagrange multiplier (error) & 0.0083 & & \\
\hline Robust LM (error) & 0.1787 & & \\
\hline Likelihood ratio test & & 0.0528 & 0.0079 \\
\hline
\end{tabular}

Note: ${ }^{*} p<.05,{ }^{* *} p<.01,{ }^{* * *} p<.001$. OLS: ordinary least squares; SLM: spatial lag model; SEM: spatial error model; LM: Lagrange multiplier.

\section{Conclusion}

We analysed Seoul Metropolitan City's dong-unit database and obtained the following results. First, while the SEM is suitable for analysing multi-unit housing prices, the SLM is suitable for single-unit housing and apartment prices. Second, private educational facilities and art museums have positive influences on most housing prices, while historical sites have a negative influence. Finally, public libraries and urban park areas have negative effects on apartment prices. Thus, this study can imply that historical sites, public libraries, and urban park areas can be interpreted as less influential factors in housing prices compared to private educational facilities and art museums.

Table 9 presents a comparison of our research results with those of $\mathrm{Ki}$ and Sung (2020). Both studies adopted the same independent variables but at different spatial scales: the residents' immediate neighbourhood (dong) and the residential district (gu), respectively. The test of the SLM is more robust in terms of residents' immediate neighbourhood (dong) analysis, especially between single-unit housing and apartments, suggesting that the most proximate public facilities can be considered a relevant factor in explaining residential housing prices, which is also consistent with the results of Wittowsky et al. (2020).

Based on this comparison, we suggest the following policy implications. First, private educational facilities positively influence all types of housing at the $g u$ and dong levels, which is a finding consistent with most of the previous studies (Cho et al., 2020; Ha and Lee, 2013; Kim and Kim, 2019). The residents of Seoul closely associate private educational facilities with students' academic performance and consider them as essential educational facilities (Ha and Lee, 2013). Consequently, parents of students tend to relocate close to private educational facility clusters (Park and Lee, 2011) to allow easy access to education for their children, thereby positively influencing housing prices in Seoul at both the $g u$ and dong levels.

Second, art and general museums have positive effects on the prices of all housing types in a residential district $(g u)$. Art museums have a positive effect on single- and multi-unit housing prices in residents' immediate neighbourhood (dong). In particular, art museums positively affect social and educational environmental satisfaction, and in turn, residential environmental satisfaction (Ki and Sung, 2020). For example, a recent study (Han, 2020) suggested that art museums have 
Table 9. Comparison of research results

\begin{tabular}{|c|c|c|c|c|}
\hline \multirow{2}{*}{\multicolumn{2}{|c|}{ Dependent Variables }} & \multicolumn{3}{|c|}{ Spillover Effects of Independent Variables } \\
\hline & & Best Model & Positive Effects & Negative Effects \\
\hline \multirow{3}{*}{$\begin{array}{c}\text { Residents' immediate } \\
\text { neighbourhood } \\
(\text { dong })\end{array}$} & Multi-unit housing & SEM & Private educational facility, art museum & Historical site \\
\hline & Single-unit housing & SLM & Private educational facility, art museum & Historical site \\
\hline & Apartment & SLM & Private educational facility & Public library, urban park area \\
\hline \multirow{3}{*}{$\begin{array}{l}\text { Residential district } \\
\qquad(g u)\end{array}$} & Multi-unit housing & SEM & Private educational facility, art museum, museum & Historical site, urban park area \\
\hline & Single-unit housing & SEM & Private educational facility, art museum, museum & Historical site, urban park area \\
\hline & Apartment & SEM & Private educational facility, art museum, museum & Public library, historical site, urban park area \\
\hline
\end{tabular}

Note: SLM: spatial lag model, SEM: spatial error model.

gained in popularity as art education program venues for nearby elementary schools. Therefore, the art museums in Seoul serve not only as exhibition spaces but also as educational facilities. Additionally, another study (Seresinhe et al., 2016) showed that the image of art represented by art museums can affect housing prices. These findings indicate that the accessibility of art and general museums reflects residents' needs and preferences, and in turn, influences housing prices.

Third, public libraries negatively influence apartment prices at both the $g u$ and dong levels. This implies that the perception of public libraries needs to change from 'book lending library' to 'community cultural complex' (Noh and Kim, 2019). Notably, residents regard public libraries as community spaces for cultural activities (Seoul Metropolitan City, 2019). If public libraries do not meet their expectations, they lose their appeal and fail to motivate residents to work within the community for cultural reinforcement (Adkins and Hussey, 2006), which would have an adverse effect on apartment prices. Although apartment residents accept public libraries as a type of educational facility, they consider them less important than private educational facilities. Therefore, public libraries are required to serve as both educational and cultural facilities for residents. Enduring efforts and prompt support from both local and central governments are necessary to achieve this conversion for public libraries. Beyond this, policy-makers could adopt measures to transform public libraries from basic facilities to complex systems with various educational and cultural programs (Gu, 2019; Seoul Metropolitan City, 2019).

Fourth, historical sites negatively influence the prices of most housing types, at both the gu and dong levels. Historical sites are often perceived as a hindrance to local physical development (Been et al., 2014) because the disadvantages of construction restrictions appear to outweigh their cultural benefits, thus adversely affecting social environment satisfaction (Ki and Sung, 2020). In other words, historical sites fail to attract public interest as cultural heritage sites (Hyundai Research Institute, 2018), due to the lack of understanding of the inherent value and information they provide (Korea Cultural Heritage Administration, 2018). To address this, public efforts must be made to improve the quality of the interpretive content of signs, interpretation of cultural heritage, and relevant cultural programs to help residents appreciate the value of historical sites.

Finally, urban park areas negatively affect the prices of all housing types at the $g u$ level, and of apartment prices at the dong level. Although urban parks were initially created to meet residents' needs (Kim et al., 2006), negative externalities, such as noise or disturbances from frequently used community sports facilities in the park, can cause inconvenience to residents, adversely affecting cultural environmental satisfaction (Ki and Sung, 2020) and in turn, the housing prices in the area (Lin, 2016). For instance, apartment residents often register civil complaints against park users due to noise disturbances (Sung and Ki, 2021). In particular, considering that most apartments in Seoul Metropolitan City have their own green spaces, urban park areas - which negatively affect apartment prices at the dong level - seem unnecessary. Therefore, urban park planners must find alternative means to minimize negative externalities, such as employing landscape treatments to screen out disturbances (More et al., 1988).

Despite the significance of this study, we acknowledge its limitations. First, we assumed that the 'other location factors' in the spatial dataset are similar, because Seoul's dong-level 
spatial characteristics share many common elements, such as population, housing structure, and CBD accessibility. Second, this study used cross-sectional data from 2016 without conducting a time-series analysis, owing to a lack of longitudinal data. Spatial dependence in apartment transaction prices could vary over boom or bust periods (Hyun and Milcheva, 2018), and this aspect should be examined in future research using additional data.

\section{References}

Abidoye, R.B. and A.P. Chan. 2017. Critical review of hedonic pricing model application in property price appraisal: a case of Nigeria. Int. J. Sustain. Built Environ. 6(1):250-259. https://doi.org/10.1016/j.ijsbe.2017.02.007

Adair, A., S. McGreal, A. Smyth, J. Cooper, and T. Ryley. 2000. House prices and accessibility: the testing of relationships within the Belfast urban area. Hous. Stud. 15(5):699-716. https://doi.org/10.1080/02673030050134565

Adair, A.S. and W.S. McGreal. 1994. Local housing markets, structure and buyer behaviour: the east Belfast case. Scand. Hous. Plann. Res. 11(1):27-38. https://doi.org/10.1080/0 2815739408730346

Adkins, D., and L. Hussey. 2006. The library in the lives of Latino college students. Libr. Q. 76(4):456-480.

Ahlfeldt, G.M., N. Holman, and N. Wendland. 2012. An assessment of the effects of conservation areas on value. London: LSE and English Heritage. Retrieved from https:/ /historicengland.org.uk/content/docs/research/assessmen t-ca-value-pdf/

Been, V., I.G. Ellen, M. Gedal, E. Glaeser, and B.J. McCabe. 2014. Preserving history or hindering growth? the heterogeneous effects of historic districts on local housing markets in New York city. Natl. Bur. Econ. Res. 20446:1-58. https://doi.org/10.3386/w20446

Bramley, G., C. Leishman, and D. Watkins. 2008. Understanding neighbourhood housing markets: regional context, disequilibrium, sub-markets and supply. Hous. Stud. 23(2):179-212. https: //doi.org/10.1080/02673030701875113

Brueckner, J.K., J.F. Thisse, and Y. Zenou. 1999. Why is central Paris rich and downtown Detroit poor? an amenity-based theory. Eur. Econ. Rev. 43(1):91-107. https://doi.org/10.

\section{6/S0014-2921(98)00019-1}

Cai, Y., Y. Zhu, F. Yuan, J. Gao, and M. Helbich. 2020. Urban housing prices and regional integration: a spatial analysis in the city of Kaifeng, China. Appl. Spat. Anal. Policy 14:355-378. https://doi.org/10.1007/s12061-020-0 9367-y

Chin, T.L. and K.W. Chau. 2003. A critical review of literature on the hedonic price model. Int. J. Hous. Appl. 27(2): 145-165.

Cho, Y.S., J.H. Lee, and H.B. Kim. 2020. The influence of the educational infrastructure access on housing value: focused on the private academy street, Junggye, Seoul. J. Urban Des. 21(6):5-14. https://doi.org/10.38195/judik. 2020.12.21.6.5

Chun, H.J. 2016. A study on estimation of housing price using GWR model and GIS technology. Resid. Environ. 14(1):1-12.

Decoville, A. and O. Klein. 2020. Polycentrism and the accessibility of public facilities to the population. The example of the Grand Duchy of Luxembourg and Belval. Eur. Plan. Stud. 28(4):653-671. https://doi.org/10.1080/09654313.2019.1 670141

Dong, G., L. Wolf, A. Alexiou, and D. Arribas-Bel. 2019. Inferring neighbourhood quality with property transaction records by using a locally adaptive spatial multi-level model. Comput. Environ. Urban Syst. 73:118-125. https: //doi.org/10.1016/j.compenvurbsys.2018.09.003

Feng, Y., Wei, D.Y., and Wu, J. 2020. Amenity effects of urban facilities on housing prices in China: accessibility, scarcity, and urban spaces. Cities 96:102433.

Government of the Republic of Korea. 2018a. Partial revision of the national urban regeneration framework: revised the national minimum standards for basic living infrastructure. Sejong: Korea Ministry of Land, Infrastructure, and Transport (2018-1790). Retrieved from http://www.molit.go.kr/US R/NEWS/m_71/dtl.jsp?id=95081697

Government of the Republic of Korea. 2018b. Museum and art gallery support act 2018, c. 1. Retrieved from https://www.1 aw.go.kr/LSW/eng/engLsSc.do?menuId=2\&section=la $w N m \&$ query $=$ museum $\& x=30 \& y=30 \# 1$ iBgcolor 11 .

Government of the Republic of Korea. 2019. Three-year life SOC plan (2020-2022). Sejong: Office for Government Policy Coordination of South Korea. Retrieved from https://ww w.opm.go.kr/opm/info/soc04.do?mode=download\&artic 
leNo $=122059 \&$ attachNo $=92571$

Government of the United Kingdom. 2021. New research will demonstrate benefit of culture and heritage to society. Retrieved from https://www.gov.uk/government/news/new-researchwill-demonstrate-benefit-of-culture-and-heritage-to-society

$\mathrm{Gu}$, N. 2019. Korean apartment complexes and social relationships of the residents. Hous. Stud. 35(8):1362-1389. https://doi.org/10.1080/02673037.2019.1667491

Ha, Y.J., and W.H. Lee. 2013. The relationship between educational environment and housing prices and its implication for socio-spatial inequality: the case of Seoul, Korea. J. Econ. Geogr. Soc. Korea. 16(1):86-98.

Han, J.Y. 2020. A study on the art education expertise and art museum education in Korea: focusing on docents, educators, and school teachers. Doctoral dissertation. University of Seoul National University, Republic of Korea.

Hyun, D. and S. Milcheva. 2018. Spatial dependence in apartment transaction prices during boom and bust. Reg. Sci. Urban Econ. 68:36-45. https://doi.org/10.1016/j.reg sciurbeco.2017.11.001

Hyundai Research Institute. 2018. A survey report on cultural heritage appreciation and perception in 2018. Daejeon: Korea Cultural Heritage Administration. http://116.67.8 3.213:18080/streamdocs/view/sd;streamdocsId $=720592$ 27039208754

Jeon, S. I. 2015. The present situation and prospect of the spread of apartment housing. Technical Report No. 8. Daejeon, South Korea: Korean National Statistical Office. Retrieved from https://kostat.go.kr/sri/srikor/srikor_pbl/ 3/index.board?bmode=read\&aSeq $=370164$

Jin, Y.N. and J.Y. Sohn. 2005. Education and housing prices: evidence from Seoul apartment market. Hous. Stud. Rev. 13(3):125-148.

Kang, B.S. 2014. Study on the relationship between regional amenity and housing transfer. J. Korean Urban Manag. Assoc. 27(1):193-214. https://www.dbpia.co.kr/journal/ articleDetail?nodeId=NODE02391943

Kang, M.N., H.S.Kim, M.S. Park, J.C. Lee, J.H. Kim, G.J. Lee, Y.J. Jo, J.Y. Yoo, and G.W. Lee. 2019. Korea Housing Survey. Technical Report, Sejong, South Korea: Korea Ministry of Land, Infrastructure, and Transport. Retrieved from http://stat.molit.go.kr/portal/cate/statFileView.do? hRsId=327\&hFormId $=$
Ki, J.H. and M.K. Sung. 2020. Residential performance assessment based on accessibility to local cultural and educational facilities: A study of impact factors with spatial regression model. 2020 Spring Conference Proce edings of the Korean Regional Development Association. 3-30. http://www.krda.org/bbs/board.php?bo_table=data _seminar\&wr_id $=216$

Kim, H.J., J.G. Lee, and K.H. Yeo. 2015. Regional disparities and determinants of spatial accessibility of public libraries in Seoul. Seoul Stud. 16(4):109-127.

Kim, K.M. and Y.W. Lee. 2007. The impact of the private education market and educational performance on apartment prices since 2004. J. Korea Spat. Plan. Rev. 55:239-252.

Kim, M.Y. and E.J. Kim. 2019. Effects of neighborhood environment on multifamily housing price: focused on Seoul Metropolitan City in Korea. J. Korean Geog. Soc. 22(1):163-175.

Kim, S.J., D.S. Lee, and C.Y. Yoon. 2006. A study on the need facilities according to usual characteristics of urban park. J. Korean Inst. Rural Arch. 8(2):27-35.

Kim, S.W. and K.S. Chung. 2010. The study of spatial weight matrix reflecting true reality in the spatial econometrics model: focused on the real transaction housing price in the Busan. Hous. Stud. Rev. 18(4):59-80.

Kim, Y.S. 2012. Empirical analysis on influence of education performance on housing prices: a case of Daegu. Hous. Stud. Rev. 20(3):205-230.

Korea Cultural Heritage Administration. 2018. Cultural heritage interpretive sign content guidelines by case study. Daejeon: Korea Cultural Heritage Administration. http://116.67.8 3.213:18080/streamdocs/view/sd;streamdocsId=720592 27040178099

Kulish, M., A. Richards, and C. Gillitzer. 2012. Urban structure and housing prices: Some evidence from Australian cities. Econ. Rec. 88(282):303-322. https://doi.org/10.1111/j.1 475-4932.2012.00829.x

Lan, F., Q. Wu, T. Zhou, and H. Da. 2018. Spatial effects of public service facilities accessibility on housing prices: a case study of Xi'an, China. Sustainability 10(12):4503. https://doi.org/10.3390/su10124503

Lee, H.Y. and S.C. Noh. 2013. Advanced statistics analysis: Theory and practice. Seoul, Republic of Korea: Moonwoo Publisher. https://url.kr/tbopvr 
Lee, K.H. 2010. Effects of school district reputation, educational input and outcome variables on apartment price. Hous. Stud. Rev. 18(1):69-88.

Li, H., Y.D. Wei, Y. Wu, and G. Tian. 2019. Analyzing housing prices in shanghai with open data: amenity, accessibility and urban structure. Cities 91:165-179. https://doi.org/10.10 16/j.cities.2018.11.016

Lin, I.H. 2016. Assessing the effect of parks on surrounding property values using hedonic models and multilevel models. Doctoral dissertation, University of Wisconsin-Milwaukee.

Lord, G.D. and N. Blankenberg. 2016. Cities, museums and soft power. Virginia: American Alliance of Museums Press.

Maeer, G., A. Robinson, and M. Hobson. 2016. Values and benefits of heritage: a research review. London: Heritage Lottery Fund. Retrieved from https://arc.global/articles/ docs/heritage-its-good-for-you/values_and_benefits_of_ heritage_2015--cite-2001.pdf

More, T.A., T. Stevens, and P.G. Allen. 1988. Valuation of urban parks. Landsc. Urban Plan. 15(1-2):139-152. https: //doi.org/10.1016/0169-2046(88)90022-9

Moro, M., K. Mayor, S. Lyons, and R.S. Tol. 2013. Does the housing market reflect cultural heritage? a case study of greater Dublin. Environ. Plan. A. 45(12):2884-2903. https://doi.org/10.1068/a45524

Noh, Y.H. and Kim Y.J. 2019. A study on the user recognition of library complex culture space. J. Korean Soc. Libr. Inf. Sci. 53(4):23-50. https://doi.org/10.4275/KSLIS.201 9.53.4.023

Oh, P.R. 2014. A study on travel characteristics and the establishment of criterion for the size of the neighbourhood unit by using the data of household travel diary survey in Seoul. Seoul Stud. 15(3):1-18.

Park, G.B. and Ham, Y.J. 2018. A study using spatial regression models on the determinants of the welfare expenditure in the local governments in Korea. J. Digit. Converg. 16(10): 89-99. https://doi.org/10.14400/JDC.2018.16.10.089

Park, J.H., D.K. Lee, C. Park, H.G. Kim, T.Y. Jung, and S. Kim. 2017. Park accessibility impacts housing prices in Seoul. Sustainability 9(2):185. https://doi.org/10.3390/s u9020185

Park, S.H. and K.S. Lee. 2011. Spatial characteristics of the provision of and demand for private tutoring service industries in the metropolitan Seoul area. J. Econ. Geog.
Soc. Korea 14(1):33-51.

Reilly, S., C. Nolan, and L. Monckton. 2018. Wellbeing and the historical environment. London: Historic England. Retrieved from https://historicengland.org.uk/images-bo oks/publications/wellbeing-and-the-historic-environment/

Rey, S.J., W. Kang, and L. Wolf. 2016. The properties of tests for spatial effects in discrete Markov chain models of regional income distribution dynamics. J. Geog. Syst. 18(4):377-398. https://doi.org/10.1007/s10109-016-0234-x

Rudokas, K., M. Landauskas, I. Gražulevičiūtè-Vilneiškè, and O. Viliūnienè. 2019. Valuing the socio-economic benefits of built heritage: local context and mathematical modelling. J. Cult. Herit. 39:229-237. https://doi.org/10.1016/j.culh er.2019.02.016

Sagger, H., J. Philips, and M. Haque. 2021. Valuing culture and heritage capital: a framework towards information decision making. London: the UK department for digital, culture, media and sport. Retrieved from https://www.go v.uk/government/publications/valuing-culture-and-herita ge-capital-a-framework-towards-decision-making/valui ng-culture-and-heritage-capital-a-framework-towards-in forming-decision-making

Seo, M.H., J.S. Lee, and Y. Choi. 2016. Estimation of the natural damage disaster considering the spatial autocorrelation and urban characteristics. J. Korean Soc. Civ. Eng. 36(4): 723-733. https://doi.org/10.12652/Ksce.2016.36.4.0723

Seo, S.B. 2014. A study on the spatial autocorrelation of land price variation and trading volume. J. Koran Plan. Assoc. 49(8):25. https://doi.org/10.17208/jkpa.2014.12.49.8.21

Seoul Metropolitan City. 2019. 2030 Seoul Metropolitan City community planning. Seoul: Seoul Metropolitan City. https:// planning.seoul.go.kr/plan/map/getPlanMap.do

Seresinhe, C.I., T. Preis, and H.S. Moat. 2016. Quantifying the link between art and property prices in urban neighbourhoods. R. Soc. Open Sci. 3(4):160146. https://doi.org/10.1098/rs os. 160146

Smith, N.B., A. Venerandi, and K. Toms. 2017. Beyond location (Create Streets). Retrieved from https://www.createstreets. com/projects/create-streets-latest-report-beyond-location -published/

Sung, M. and J. Ki. 2021. Influence of educational and cultural facilities on apartment prices by size in Seoul: do residents' preferred facilities influence the housing market? Hous. Stud. Advanced Online Publication 1-27. https://doi.org/ 


\section{$10.1080 / 02673037.2021 .1908962$}

Van Duijn, M., and J. Rouwendal. 2012. Analysis of household location behaviour, local amenities and house prices in a sorting framework. J. Prop. Res. 29(4):280-297. https://doi.org/10.1080/09599916.2012.717100

Ward, M.D. and K.S. Gleditsch. 2008. Spatial regression models. Series: Quantitative applications in the social sciences. Thousand Oaks, CA: Sage.

Weill, S. 2002. Making Museums Matter. Washington: Smithsonian Books.

Wittowsky, D., J. Hoekveld, J. Welsch, and M. Steier. 2020. Residential housing prices: Impact of housing characteristics, accessibility and neighbouring apartments: a case study of Dortmund, Germany. Urban Plan. Transp. Res. 8(1):4470. https://doi.org/10.1080/21650020.2019.1704429

Yim, S.J. and C.H. Kim. 2020. Analysis of selecting an appropriate location for infrastructure considering the range of service area and accessibility: focusing on public libraries. J. Korean Reg. Dev. Assoc. 32(3):45-66.

Yuan, F., Y.D. Wei, and J. Wu. 2020. Amenity effects of urban facilities on housing prices in china: accessibility, scarcity, and urban spaces. Cities 96:102433. https://doi.org/10.1 016/j.cities.2019.102433

Zahirovic-Herbert, V. and K.M. Gibler. 2020. Neighbouring house transaction response to assisted living facilities and nursing homes. Hous. Stud. 35(2):195-221. https://d oi.org/10.1080/02673037.2019.1594714 